\title{
The Mechanical Activation of Crystal and Wooden Sawdust Cellulose in Various Fine-Grinding Mills
}

\author{
Andrey V. Pestunov, \\ Andrey O. Kuzmin ${ }^{\text {a,b }}$, Dmitriy A. Yatsenko, \\ Margarita Kh. Pravdina ${ }^{c}$ and Oxana P. Taran ${ }^{\mathrm{a}, \mathrm{d} *}$ \\ ${ }^{a}$ Boreskov Institute of Catalysis \\ 5 Lavrentieva, Novosibirsk, 630090, Russia \\ ${ }^{b}$ Novosibirsk State University \\ 2 Pirogova Str., Novosibirsk, 630090, Russia \\ 'Institute of Thermophysics \\ 1 Lavrentieva pr., Novosibirsk, 630090, Russia \\ ${ }^{d}$ Novosibirsk State Technical University \\ 20 K. Marksa, Novosibirsk, 630092, Russia
}

Received 28.04.2015, received in revised form 21.06.2015, accepted 04.07.2015

The study is aimed to determine the most perspective and effective fine-grinding mills for lignocellulosic biomass mechanical activation. Physicochemical characteristics were studied for milled crystalline cellulose and milled dry birch sawdust after their treatment in various devices - ball, planetary, ring, vortex gas driven and vortex mechanically driven mills. XRD analysis method was used for phases identification, crystallinity index (CI) and mean size of coherent-scattering region (CSR) measuring. These values are suggested to be used for an assessment of the efficiency of mechanical activation process. Mean particle size (l) of milled materials was measured with help of optic microscopy as well. As the most perspective device for future detailed investigation to be done the vortex mechanically driven mill is selected. This type of mill provides both the least electrical power consumption and activation time at adequate particles destruction level and marked mechanical activation demonstrated for dry birch saw dust (it was detected the reduction of $l$ and CI from $l \sim 3700 \mu \mathrm{m} / \mathrm{CI}=74 \%$ to $l \sim 22 \mu \mathrm{m} / C I=56 \%$.

Keywords: lingocellulosic biomass, cellulose, activation, vortex mill, planetary mill.

DOI: $10.17516 / 1998-2836-2015-8-3-386-400$.

(C) Siberian Federal University. All rights reserved

* Corresponding author E-mail address: oxanap@catalysis.ru 


\title{
Механическая активация чистой \\ и содержащейся в древесных опилках целлюлозы \\ в мельницах различного типа
}

\author{
А.В. Пестунов ${ }^{\mathrm{a}, \tilde{\sigma}}$, А.О. Кузьмин ${ }^{\mathrm{a}, \boldsymbol{\sigma}}$, \\ Д.А. Яценко

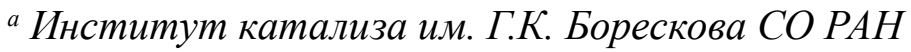 \\ Россия, 630090, Новосибирск, пр. Лаврентьева, 5 \\ ${ }^{\sigma}$ Новосибирский государственный университет \\ Россия, 630090, Новосибирск, ул. Пирогова, 2 \\ ${ }^{8}$ Институт теплофизики СО РАН \\ Россия, 630090, Новосибирск, пр. Лаврентьева, 1 \\ ${ }^{2}$ Новосибирский государственный технический университет \\ Россия, 630092, Новосибирск, пр. К. Маркса, 20
}

Для выбора наиболее эффективного способа механической активачии биомассы проведено предварительное исследование процесса измельчения и механической активачии образиов кристаллической целлюлозы и лигноцеллюлозной биомассы (высушенные березовые опилки) в мельницах различных конструкций (вальцовая, планетарная, роторная, вихревая газодинамическая и вихревая с механическим разгоном материала) с изучением физикохимических характеристик продуктов помола. Методом рентгенофазового анализа (РФА) проведена идентификачия фаз, определены индекс кристалличности (ИК) и средний размер областей когерентного рассеяния, определяющих эффективность активации биомассы. Методом оптической микроскопии исследована морфология и средний размер частии (l). В качестве наиболее перспективного для последующего более детального изучения выбран метод активации лигночеллюлозной биомассы в ударной вихревой мельнице с механическим разгоном материала, как обеспечивающий минимальные затраты энергии и времени при удовлетворительной степени измельчения и активации, продемонстрированных для высушенных берёзовых опилок $(l \sim 22$ мкм и ИК $=56 \%$ при $l \sim 3700$ мкм и ИК $=74 \%$ для исходного сырья).

Ключевые слова: лигноцеллюлозная биомасса, целлюлоза, активация, вихревая мельница, планетарная мельница.

\section{Введение}

Общепризнано, что растительная биомасса может служить практически неисчерпаемой сырьевой базой для получения востребованных химических веществ и материалов, а также для производства биотоплива $[1,2]$. Так, источником лигноцеллюлозной (ЛЦ) биомассы являются отходы деревообрабатывающего и целлюлозно-бумажного производства, отходы растениеводства и пищевого производства. ЛЦ-биомассу также можно получать путём культивирования так называемых энергетических культур (тростник, мискантус, просо и др.). Основными

$$
-387-
$$


компонентами ЛЦ-биомассы являются полисахариды: целлюлоза (40-60 \%) и гемицеллюлозы (до 30 \%), а также лигнин (10-30\%), представляющий собой комплекс полимеров ароматической природы и очень сложного состава [3-5]. Поиск путей комплексной переработки биомассы (в особенности трудно перерабатываемых целлюлозы и лигнина) - в настоящее время очень важное направление научных исследований $[6,7]$.

Ферментативный гидролиз - один из наиболее перспективных способов переработки биомассы. Однако плохая растворимость и высокая устойчивость к гидролизу основного компонента ЛЦ-биомассы - целлюлозы - основное препятствие к эффективному проведению данного процесса. Причиной этого служит высокая прочность структуры целлюлозы, являющейся аморфно-кристаллическим полимером, в отличие от аморфных гемицеллюлоз и лигнина. Данное обстоятельство препятствует проведению процесса гидролиза, а использование ферментов делает невозможным использование жестких реакционных условий. Исследование текстурных характеристик показывает, что при проведении гидролиза целлюлозы её индекс кристалличности возрастает с увеличением степени конверсии в растворимые сахара [8], что может объясняться гидролизом только аморфной целлюлозы, в то время как кристаллическая составляющая значительно более устойчива к ферментативному воздействию. Таким образом, разрушение кристаллической компоненты целлюлозы есть ключевой этап в подготовке ЛЦбиомассы для каталитической и биотехнологической переработки, что требует применения методов дополнительной активации лигноцеллюлозного сырья.

В серии работ, посвященных исследованию эффективности процесса ферментативного гидролиза ЛЦ-биомассы, совмещённого с одновременным проведением механической активации (измельчающими стальными шарами), показана возможность увеличения выхода сахаров и скорости процесса гидролиза [9-11]. При этом отмечена также возможность падения скорости реакции вследствие разрушения фермента при высоких скоростях перемалывания $[10,12]$. Осуществление предварительного измельчения целлюлозы в шаровой мельнице с разрушением её кристаллической структуры также ведет к увеличению скорости гидролиза, степени конверсии, увеличению растворимости активированной целлюлозы в холодной воде [8, 13]. Более того, при проведении механической активации ЛЦ-биомассы происходит не только разрушение структуры полимеров, но и увеличение удельной площади поверхности образцов, что ведет к увеличению доступности звеньев полимеров по отношению к ферментативным катализаторам: это подтверждается данными о сильном влиянии на скорость гидролиза размера частиц субстрата и методов его активации [14].

Для выбора наиболее эффективного способа механической активации растительного сырья в настоящей работе проведено измельчение образцов кристаллической целлюлозы (фракция $<0.1$ мм, ЗАО «Вектон», Санкт-Петербург) в качестве образцового материала и ЛЦ-биомассы (высушенные березовые опилки) в мельницах различных конструкций (вальцовая, планетарная, роторная, вихревая газодинамическая и вихревая с механическим разгоном частиц) с дальнейшим исследованием физико-химических характеристик продуктов активации. Оценены удельные энергетические затраты на измельчение и активацию биомассы используемыми методами. По соотношению удельных энергетических затрат, времени обработки и эффективности измельчения/ активации биомассы в качестве наиболее перспективного для дальнейшего более детального исследования выбран метод активации в вихревой мельнице с механическим разгоном материала. 


\section{Экспериментальная часть}

Сведения об используемых мельницах

В работе использованы следующие типы мельниц: вальцовая, две планетарные, два типа вихревых и роторная. Планетарные мельницы различались потребляемой мощностью и центробежным ускорением, две вихревые мельницы - способом разгона частиц измельчаемого материала - потоком воздухом от компрессора и механически за счёт быстро вращающейся крыльчатки. Некоторые технические характеристик этих мельниц приведены ниже.

1. Вальцовая мельница дискретного действия. При вращении барабана мелющие тела (вальцы) подымаются как в шаровой мельнице, после чего падают в поле тяжести, производя в измельчаемом материале разрушение «стесненным ударом». Была произведена по заказу Института катализа СО РАН на экспериментальном заводе СО АН СССР. Потребляемая мощность 0.5 кВт. Материал барабана - керамика. Объем барабана 3 дм³. Максимальная загрузка 1 дм³.

2. Планетарная мельница дискретного действия «Активатор-4М», (3АО «Активатор» г. Новосибирск, Россия [15]). За счет планетарного движения в помольном объеме создается искусственное поле тяжести с ускорением до 150 g. Потребляемая мощность 18 кВт, масса загружаемой целлюлозы 50 г.

3. Планетарная мельница дискретного действия «Pulverizette 5» («Fristch», Idar-Oberstein, Германия [16]). Объем барабана 0.25 дм³ $^{3}$ масса загружаемой целлюлозы 15 г, диаметр шаров 20 мм, количество шаров 7 шт., потребляемая мощность 1.5 кВт, ускорение в искусственном поле тяжести $22 \mathrm{~g}$.

4. Лабораторная вихревая мельница непрерывного действия с газодинамическим разгоном частиц ВМ-70 (научно-производственное предприятие «ВМ», РФ [17]). Давление сжатого воздуха 0.2-0.6 МПа, расход воздуха 1.5-2.5 кг/мин. Производительность 1-5 кг/ч.

5. Вихревая мельница непрерывного или дискретного действия с механическим разгоном материала ВМЭ-350 (Научно-производственное предприятие «ВМ», РФ [18, 19]). Установленная мощность 9 кВт. Частота вращения ротора 9000 об/мин. Диаметр разгоняющей материал вращающейся крыльчатки 0.27 м. Скорость соударения материала с ударной поверхностью $140 \div 170$ м/с. Объём помольной камеры составляет величину около 0.005 м ${ }^{3}$, объём всей мельницы вместе с камерой сепарации - около $0.03 \mathrm{~m}^{3}$. Расход воздуха через мельницу при частоте вращения крыльчатки около 9000 об/мин составляет около 650 м³/ч. Производительность до 70 кг/ч.

6. Роторная мельница МАН-30 (ЗАО «МВМ», РФ). Установленная номинальная мощность 30 кВт. Частота вращения ротора 3000 об/мин. Производительность до 100 кг/ч.

Принцип действия планетарных и вальцовых мельниц широко известен, поэтому обсудим особенности измельчения только в вихревых мельницах. Обычно все ударные измельчители работают при больших скоростях обрабатываемого материала, при которых, его разрушение происходит за одно-два соударения. Однако для вихревых мельниц описан каскадный механизм низкоскоростного измельчения, при котором частицы измельчаемого материала соударяются с преградой - боковой поверхностью помольной вихревой камеры, перемещаясь по многоугольной траектории [20-22]. Соударения с преградой (свободный удар) происходят при скоростях, близких к порогу разрушения, что обеспечивает минимум затрат энергии на собственно разрушение материала. Данное обстоятельство может быть качественно проиллюстрировано

$$
-389-
$$


зависимостью затрат энергии на единицу новой поверхности от скорости соударения частиц с преградой [23]. Для каждого материала имеется своя пороговая скорость соударения, ниже которой частица данного размера не разрушается, и существует близкая к пороговой скорость, которая обеспечивает минимум затрат энергии на создание новой поверхности.

Особенность газодинамической вихревой мельницы ВМ-70 состоит в том, что частицы в ней разгоняются постепенно, от удара к удару, пока не превышается пороговая скорость, после чего происходит деление на два-три осколка, затем процесс возобновляется (каскадный механизм). Отличием этой мельницы от всех остальных является отсутствие нагрева обрабатываемого материала, напротив, материал охлаждается. Так называемый низкоскоростной каскадный механизм измельчения выделил вихревую мельницу ВМ-70 из класса струйных мельниц, обеспечив ей отдельную нишу применения - измельчение материалов, не допускающих даже локального кратковременного разогрева. Это измельчение биопрепаратов, лекарственного сырья, термопластичных полимеров. Благодаря каскадному измельчению было обеспечено основное отличие от струйных мельниц - более низкое давление на входе: 0,3...0,6 МПа вместо 0,7...1,4 МПа. К недостаткам вихревой мельницы «ВМ» относится неэффективный с точки зрения затрат энергии способ ускорения частиц с помощью сжатого воздуха с характерным соот-

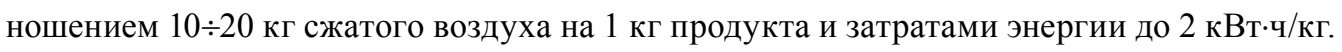

Вихревая мельница с механическим разгоном материала «ВМЭ-350» отличается от мельниц «ВМ» способом первоначального ускорения частиц при сохранении всех остальных особенностей устройства. В ней используется крыльчатка, вращающаяся внутри вихревой помольной камеры, на краях которой обеспечивается требуемая скорость соударения частиц с боковой ударной поверхностью (для используемой экспериментальной мельницы «ВМЭ-350» составляет величину около $140 \div 170$ м/с). За счёт вращения этой же крыльчатки происходит питание мельницы воздухом, необходимым для восстановления скорости частицы после ее соударения с преградой и для разгрузки мельницы. После выхода из помольной камеры материал попадает в нижнюю по потоку сепарационную камеру, отделённую от помольной камеры диафрагмой, с помощью которой, в частности, регулируется время нахождения частиц в помольной камере. Следует отметить, что в мельнице типа «ВМЭ» в отличие от «ВМ» воздух и продукты помола нагреваются и обычно предпринимаются меры для поддержания температуры около $60 \div 70^{\circ} \mathrm{C}$.

\section{Методы физико-химического анализа образиов}

Анализ фазового состава биомассы и степени кристалличности целлюлозы проводился методом рентгенофазового анализа (РФА) с определением индекса кристалличности (ИК) и области когерентного рассеяния (ОКР). Дифракционные картины получены на порошковом рентгеновском дифрактометре D8 Advance (вертикальный гониометр $\theta / 2 \theta$-геометрии) фирмы Bruker (Германия) с линейным полупроводниковым энегродисперсионным детектором LynxЕуе с никелевым фильтром на медном излучении, средняя длина волны $\mathrm{CuK} \alpha=0.154184$ нм $\left(\mathrm{CuK \alpha}_{1}=0.15406\right.$ нм, $\mathrm{CuK \alpha} \alpha_{2}=0.154439$ нм$)$. Ток рентгеновской трубки 40 мА, напряжение $40 \mathrm{~B}$ (мощность 1.6 кВт). Съемка проводилась в режиме фокусировки по методу Брэгга-Брентано. Диапазон съемки $4-80^{\circ}$ по $2 \theta$, шаг $0.1^{\circ}$, время накопления в точке от 3.5 до 7 с. Для анализа ИК и размеров ОКР использовали диапазон углов $10-40^{\circ} 2 \theta$.

$$
-390-
$$


Поскольку структуру целлюлозы принято рассматривать состоящей из аморфных и кристаллических областей, дифрактограммы раскладывали на отдельные пики, соответствующие кристаллической и аморфной фазе. Индексы пиков 101, 10-1, 021, 002, 040 соответствующие положениям по $2 \theta: 15.2,16.8,20.6,22.7,34.1^{\circ}$, выбраны в рамках структуры моноклинной целлюлозы типа I $\beta$ (пр. гр. P2 ${ }_{1}$, параметры решетки $\mathrm{a}=0.7784, \mathrm{~b}=0.8201, \mathrm{c}=1.038$ нм, $\gamma=96.55^{\circ}$, CCDC 810597 [24]). Аморфная фаза даёт размытое галло в области 21.5․ Индекс (степень) кристалличности целлюлозы рассчитывали путём разложения как отношение суммы площадей пиков кристаллической целлюлозы к суммарной площади всех пиков: ИК $=\left(I-I_{a}\right) / I$, где $I-$ интегральная интенсивность рассеяния кристаллической и аморфной фазами, $I_{a}-$ интенсивность рассеяния аморфной фазой. Таким образом, ИК определялся как отношение суммы площадей полос с индексами 101, 10-1, 021, 002, 040, после вычитания площади широкой полосы при $\sim 21.5^{\circ}$, к общей площади дифрактограммы в области углов примерно от 10 до $40^{\circ}$ по $2 \theta$ после вычитания линии фона [25].

Для целлюлозы с высокой степенью аморфности (при степени кристаличности менее 30 50 \%) такой подход вызывает трудности определения ИК из-за сильного уширения и перекрытия пиков. Поэтому дополнительно использовали более грубый подход, связанный с измерением интенсивности только пика 002 и седловины (для аморфных образцов - точки перегиба) в области $17-19^{\circ}$ по 2ө. Использование этих двух подходов позволяет также оценить погрешность определения ИК.

Размеры областей когерентного рассеяния (ОКР) $\mathrm{D}_{\mathrm{hkl}}$ (hkl - индексы отражений) для каждого пика определяли по формуле Селякова-Шеррера [26]: $D_{h k l}=\frac{k \lambda}{\beta \cos \theta}$. Здесь: $k \approx 1-$ постоянная Шеррера, зависящая от формы кристаллита; $\lambda$ - длина волны рентгеновского излучения; $\beta$ - ширина рефлекса на полувысоте; $\theta$ - угол рассеяния. После расчетов полученные значения ОКР усреднялись по всем направлениям.

Обработку дифракционных картин проводили при помощи пакета OriginLAB Pro 8.6 и программы Fityk 0.9.8 [27]. После вычитания фона экспериментальная кривая раскладывается на ряд линий, соответствующих кристаллической фазе и галло аморфной фазы. Контуры пиков аппроксимировались функцией Гаусса, определяли их положение, интенсивность и ширину.

Определение средней длины частиц проводили методом оптической микроскопии, для этого был использован оптический микроскоп «Zeiss-Axiostar Plus» (максимальное увеличение $\mathrm{x} 100)$ и цифровой фотоаппарат Canon с матрицей 8 Мп. Обработку результатов микроскопии осуществляли в программе ImageJ.

\section{Результаты и обсуждение}

Экспериментальные данные по времени активации $t$, температуре образца $T$, средней длине частиц $l$, индексу кристалличности ИК, области когерентного рассеяния ОКР и удельной затраченной на активацию образцов энергии $E$, полученные в ходе экспериментов по механической активации чистой кристаллической целлюлозы и ЛЦ-биомассы (высушенных берёзо- 


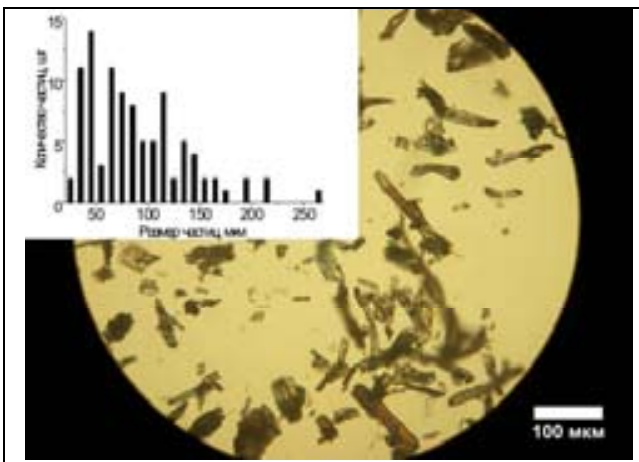

А. Исходная целлюлоза (Ц-И)
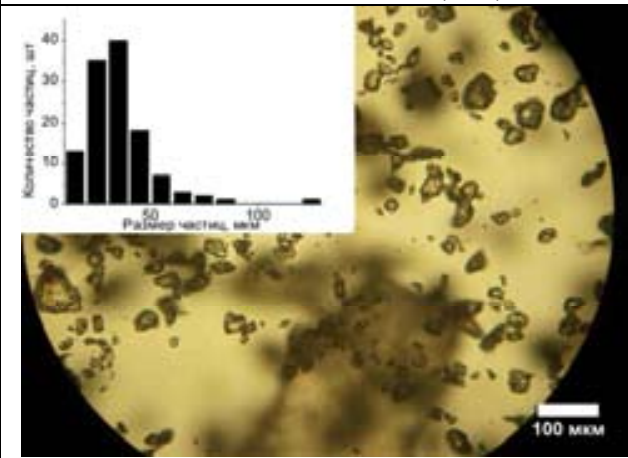

В. Целлюлоза после Pulverizette 5 (Ц-А15)

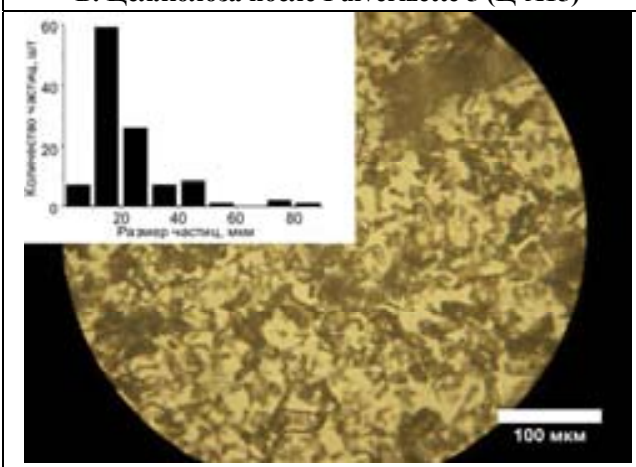

Д. Целлюлоза после ВМ-70 4.5 атм (Ц-ВМ-4-1)
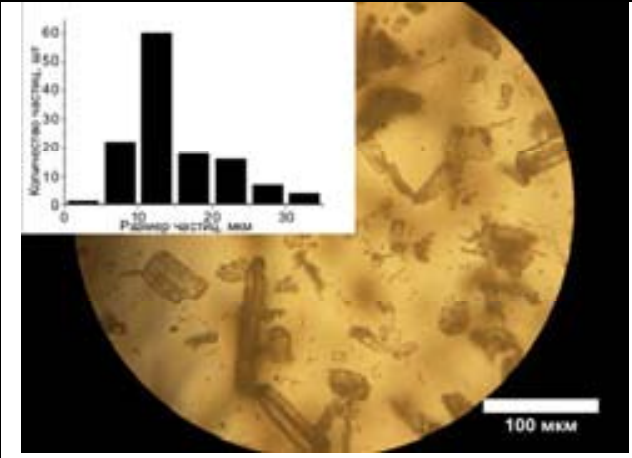

Ж. Целлюлоза после МАН-30 (Ц-МАН)

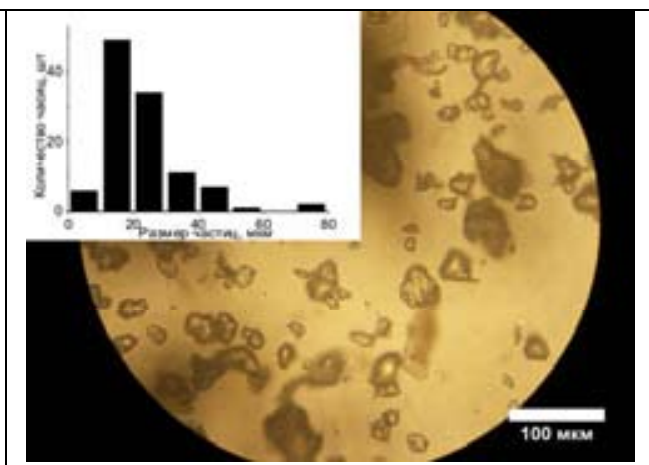

Б. Целлюлоза после «Активатор - 4М» (Ц-А)

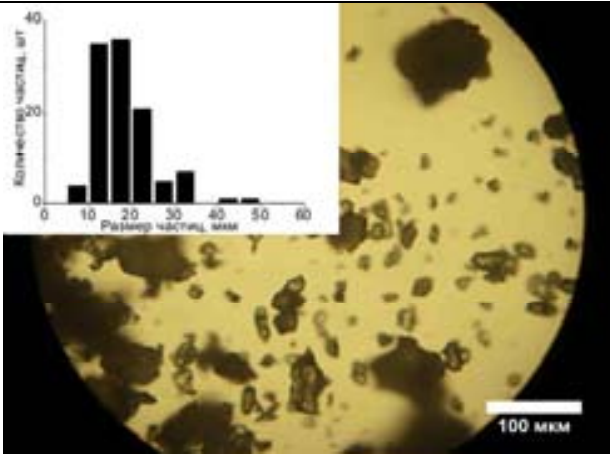

Г. Целлюлоза после Pulverizette 5 (Ц-А40)

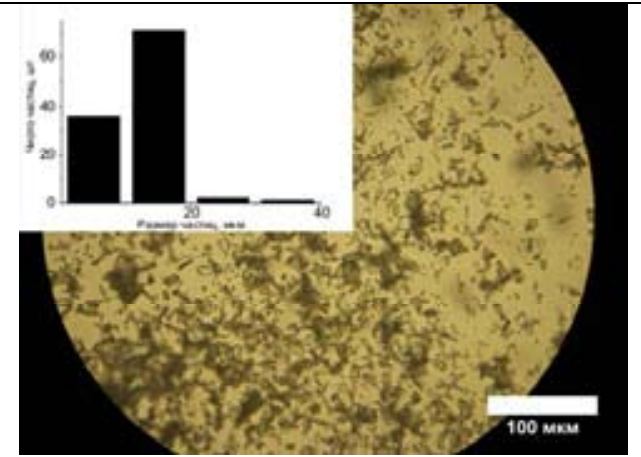

Е. Целлюлоза после ВМ-70 4.5 атм (Ц-ВМ-4-2)
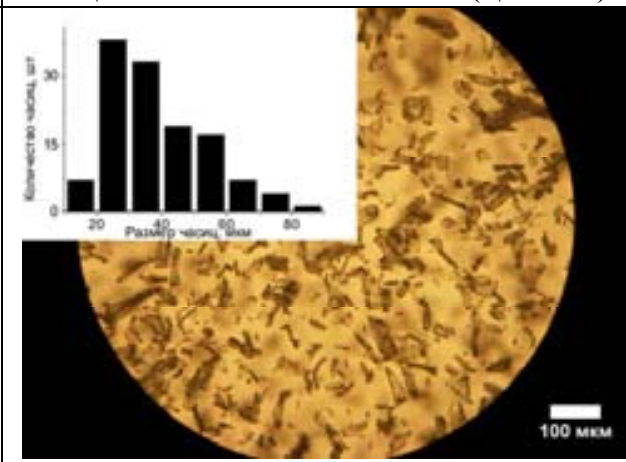

3. Целлюлоза после ВМЭ-350 (Ц-ВМЭ-350)

Рис. 1. Микрофотографии исходной целлюлозы и механически активированных образцов 


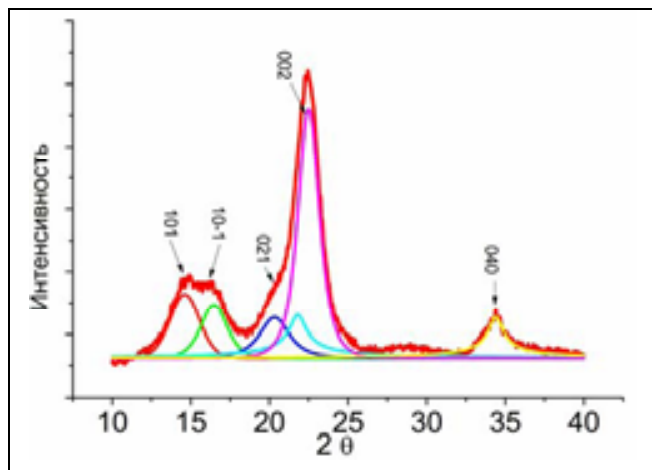

А. Исходная целлюлоза (Ц-И)

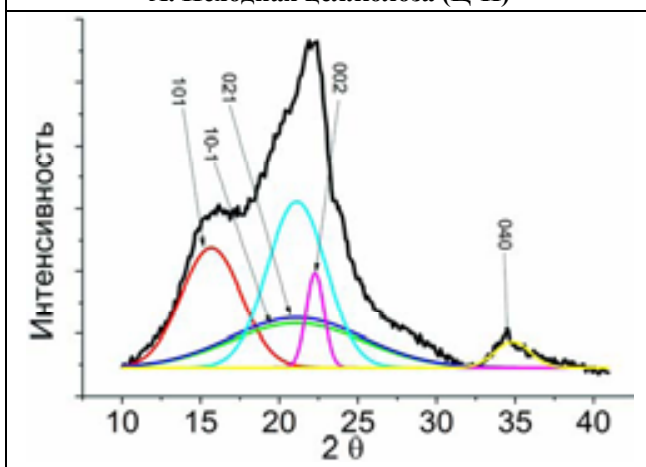

В. Целлюлоза после Pulverizette 5 (Ц-А15)

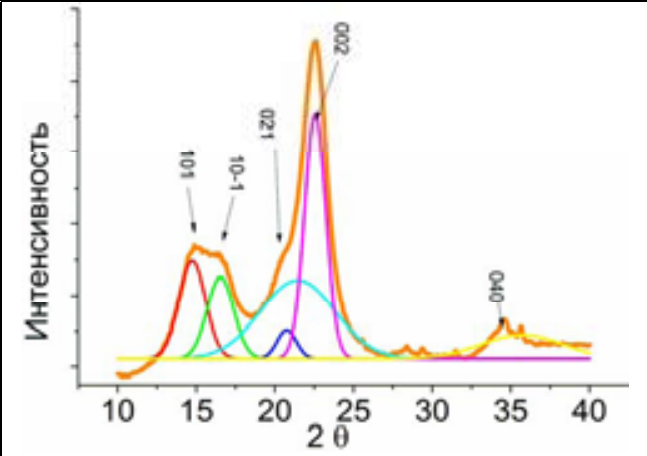

Д. Целлюлоза после ВМ-70 4.5 атм (Ц-ВМ-4-1)

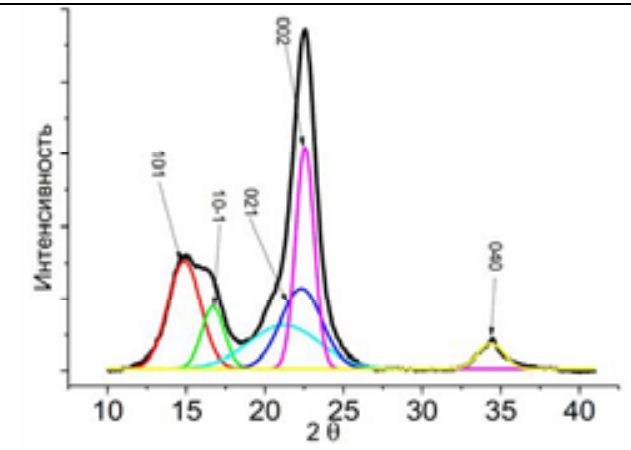

Ж. Целлюлоза после МАН-30 (Ц-МАН)

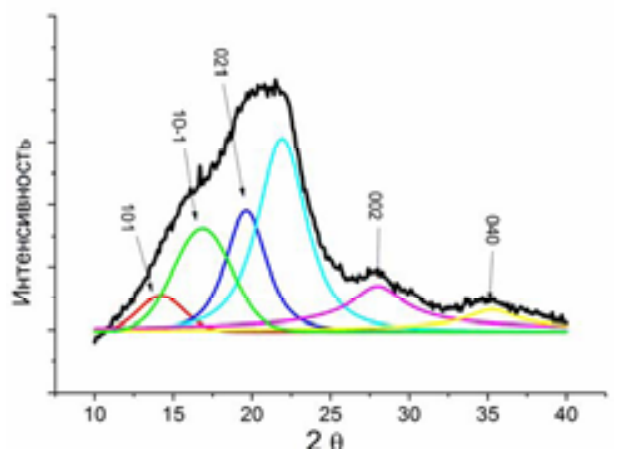

Б. Целлюлоза после «Активатора - 4М» (Ц-А)

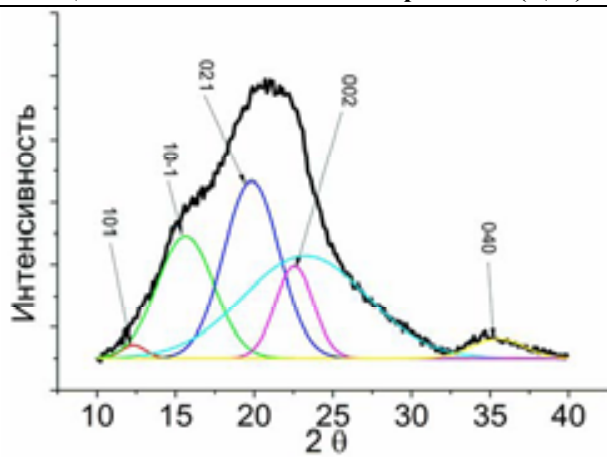

Г. Целлюлоза после Pulverizette 5 (Ц-А40)

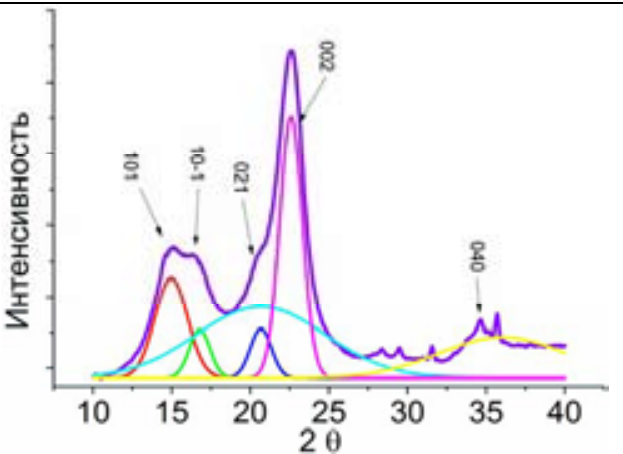

Е. Целлюлоза после ВМ-70 4.5 атм (Ц-ВМ-4-2)

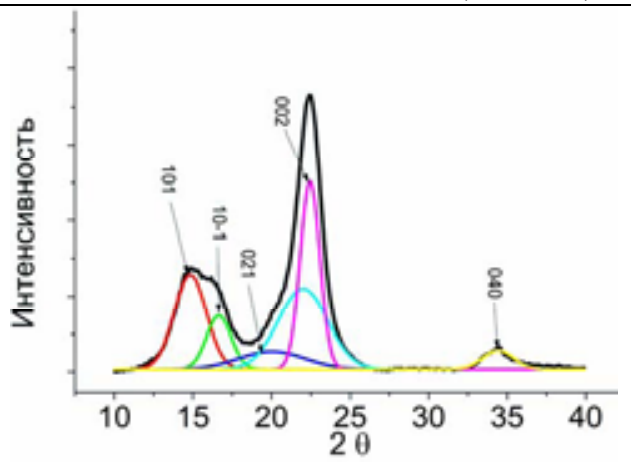

3. Целлюлоза после ВМЭ-350 (Ц-ВМЭ-350)

Рис. 2. Дифрактограммы исходной целлюлозы и механически активированных образцов 


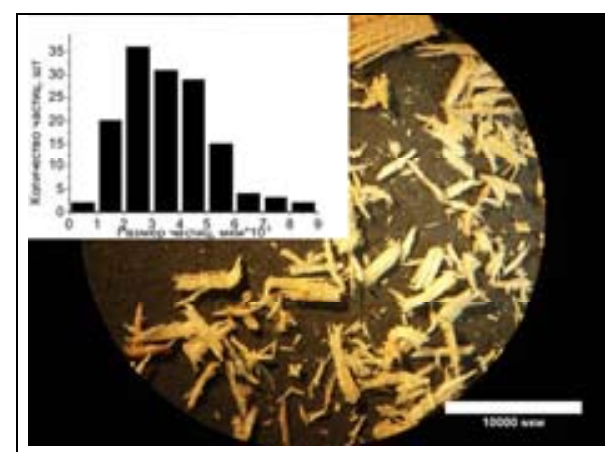

А. Береза. Исходный образец (Б-И)

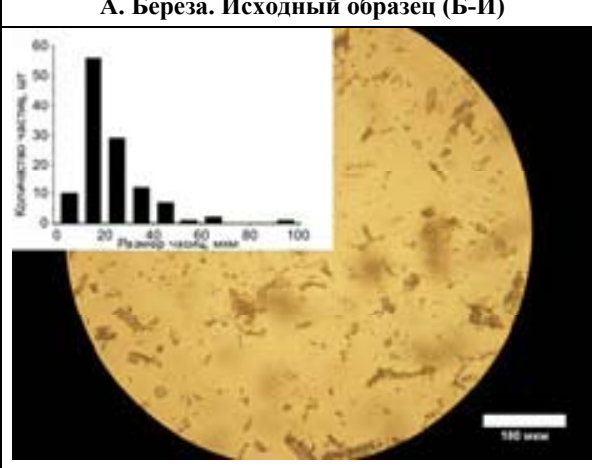

В. Береза. Образец Б-ВМЭ-350-2

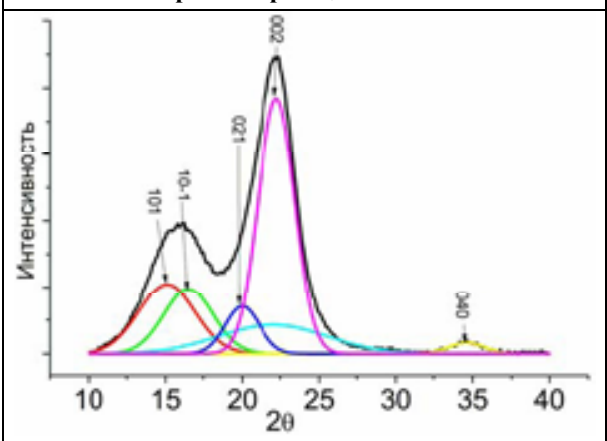

Д. Береза. Исходный образец (Б-И)

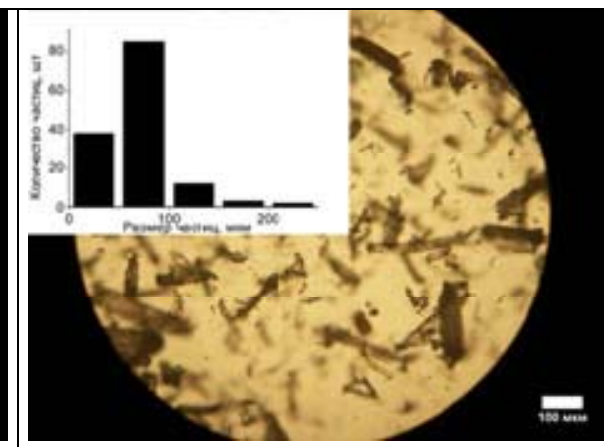

Б. Береза. Образец Б-ВМЭ-350-1

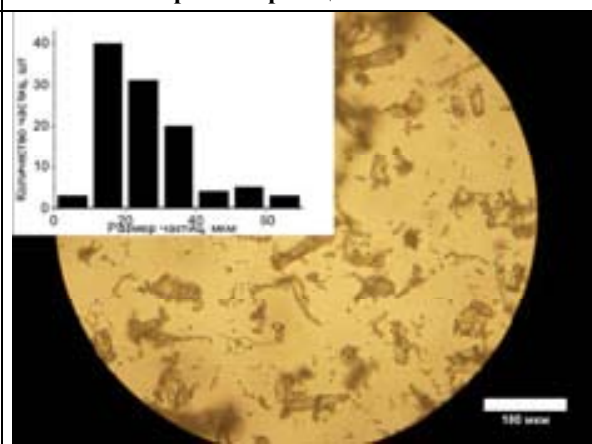

Г. Береза. Образец Б-ВМЭ-350-3

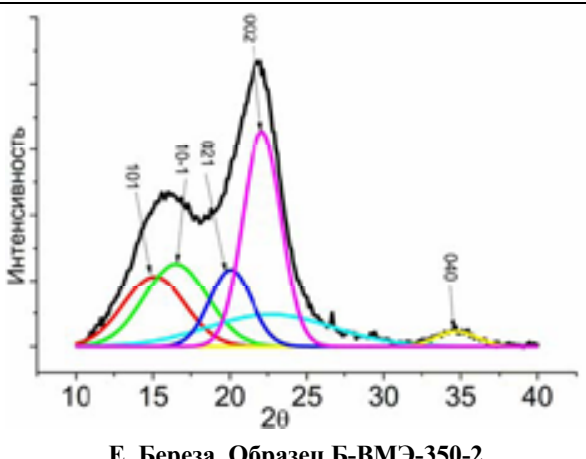

Е. Береза. Образец Б-ВМЭ-350-2

Рис. 3. Микрофотографии (А-Г) и дифрактограммы (Д-Е) исходного и механически обработанных (Е) образцов берёзовых опилок

вых опилок), представлены в таблице, а микрофотографии и дифрактограммы образцов - на рис. 1-3.

Исследованная в качестве образца сравнения микрокристаллическая целлюлоза, имеющая низкую реакционную способность при различных методах её химической обработки, характеризуется средним размером частиц 114 мкм (табл., рис. 1А). На её дифрактограмме наблюдаются рефлексы, характерные для кристаллической целлюлозы с размерами ОКР $\approx 4-7$ нм, при рассчитанном ИК $\approx 90 \%$ (табл., рис. 2 А).

Обработка целлюлозы в течение 10 ч в вальцовой мельнице приводит к уменьшению среднего диаметра частиц с 114 до 30 мкм (табл.) с сохранением в рамках погрешности кристаллической структуры образца (ИК $\approx 88$ \%) и размера ОКР (табл.). 
Таблица 1. Экспериментальные данные: время активации $t$, температура образца $T$, средняя длина частиц $l$, индекс кристалличности ИК, область когерентного рассеяния $O K P$ и удельная затраченная на активацию образцов энергия $E$ - полученные в ходе экспериментов по механической активации

\begin{tabular}{|c|c|c|c|c|c|c|c|c|}
\hline \multirow{2}{*}{ № } & \multicolumn{2}{|l|}{ Образец } & \multirow[b]{2}{*}{-} & \multirow[b]{2}{*}{$\begin{array}{l}\stackrel{\sim}{\circ} \\
\mapsto\end{array}$} & \multirow{2}{*}{$\sum_{\Sigma}^{\Sigma}$} & \multirow{2}{*}{ 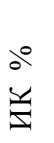 } & \multirow{2}{*}{ 章 } & \multirow{2}{*}{ 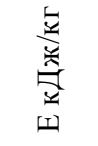 } \\
\hline & Метод обработки & Шифр & & & & & & \\
\hline \multicolumn{9}{|c|}{ Целлюлоза фракция < 0.1 мм } \\
\hline 1 & Исходная целлюлоза & Ц-И & 0 & - & $114 \pm 35$ & 90 & $4-7$ & - \\
\hline 2 & Вальцовая мельница & Ц-ВЛ & 600 мин & 25 & $30 \pm 11$ & 88 & $4-6$ & 60000 \\
\hline 3 & «Активатор - 4M» & Ц-А & 10 мин & $\sim 100$ & $5 \pm 4$ & 39 & $2-3$ & 216000 \\
\hline 4 & $\begin{array}{l}\text { Планетарная мельница } \\
\text { Pulverizette } 5\end{array}$ & Ц-Ф15 & 15 мин & $\sim 100$ & $35 \pm 20$ & 53 & $2-7$ & 72000 \\
\hline 5 & $/ /-/ /-/ /$ & Ц-Ф20 & 20 мин & $\sim 100$ & $31 \pm 10$ & 48 & $2-4$ & 96000 \\
\hline 6 & $/ /-/ /-/ /$ & Ц-Ф25 & 25 мин & $\sim 100$ & $30 \pm 12$ & - & - & 120000 \\
\hline 7 & $/ /-/ /-/ /$ & Ц-Ф30 & 30 мин & $\sim 100$ & $19 \pm 10$ & 44 & $1-3$ & 144000 \\
\hline 8 & $/ /-/ /-/ /$ & Ц-Ф35 & 35 мин & $\sim 100$ & $14 \pm 10$ & - & - & 168000 \\
\hline 9 & $/ /-/ /-/ /$ & Ц-Ф40 & 40 мин & $\sim 100$ & $13 \pm 6$ & 37 & $2-4$ & 192000 \\
\hline 10 & $\begin{array}{l}\text { Вихревая мельница } \\
\text { ВМ-70 } \\
1 \text { проход 4 5 атм }\end{array}$ & Ц- ВМ-4-1 & $1 \mathrm{c}$ & 10 & $9 \pm 2$ & 86 & $5-7$ & 3600 \\
\hline 11 & $\begin{array}{l}\text { Вихревая мельница } \\
\text { ВМ-70 } \\
2 \text { прохода 4 5 атм }\end{array}$ & Ц- ВM-4-2 & $2 \mathrm{c}$ & 10 & $8 \pm 3$ & 80 & $4-7$ & 7200 \\
\hline 12 & $\begin{array}{l}\text { Роторная мельница } \\
\text { МАН-30 }\end{array}$ & Ц-МАН & 1 мин & $\sim 50$ & $9 \pm 2$ & 91 & $2-6$ & 6000 \\
\hline 13 & $\begin{array}{l}\text { Вихревая мельница } \\
\text { ВМ-70 } \\
1 \text { проход } 5.5 \text { атм }\end{array}$ & Ц-ВМ-70-55-1 & $\sim 1 \mathrm{c}$ & 10 & $9 \pm 3$ & 89 & $1-5$ & 5000 \\
\hline 14 & $\begin{array}{l}\text { Вихревая мельница } \\
\text { ВМ-70 } \\
2 \text { прохода } 5.5 \text { атм }\end{array}$ & Ц- ВМ-70-55-2 & $\sim 2 \mathrm{c}$ & 10 & $8 \pm 3$ & 85 & $1-5$ & 10000 \\
\hline 15 & $\begin{array}{l}\text { Вихревая мельница } \\
\text { ВМ-70 } \\
3 \text { прохода } 5.5 \text { атм }\end{array}$ & Ц- ВМ-70-55-3 & $\sim 3 \mathrm{c}$ & 10 & $8 \pm 2$ & 85 & $1-5$ & 15000 \\
\hline 16 & $\begin{array}{l}\text { Вихревая мельница } \\
\text { ВМЭ-350 }\end{array}$ & Ц- ВМЭ-350 & $\begin{array}{c}\text { один } \\
\text { проход }\end{array}$ & $\sim 70$ & $39 \pm 23$ & 91 & $2-7$ & - \\
\hline \multicolumn{9}{|c|}{ Древесина березы (высушенные опилки) } \\
\hline 17 & Исходная древесина & Б-И & 0 & - & $3700 \pm 1600$ & 74 & $2-4$ & - \\
\hline 28 & $\begin{array}{l}\text { Вихревая мельница } \\
\text { ВМЭ-350 } \\
\text { (замкнутый контур) }\end{array}$ & Б- ВМЭ-350-1 & $\begin{array}{c}1 \text { мин } \\
\sim 200 \\
\text { проходов }\end{array}$ & $\sim 70$ & $69 \pm 34$ & 61 & $2-3$ & 1080 \\
\hline 19 & $\begin{array}{l}\text { Вихревая мельница } \\
\text { ВМЭ-350 } \\
\text { (замкнутый контур) }\end{array}$ & Б- ВМЭ-350-2 & $\begin{array}{c}2 \text { мин } \\
\sim 400 \\
\text { проходов }\end{array}$ & $\sim 70$ & $22 \pm 13$ & 56 & $2-3$ & 2160 \\
\hline 20 & $\begin{array}{l}\text { Вихревая мельница } \\
\text { ВМЭ-350 } \\
\text { (замкнутый контур) }\end{array}$ & Б- ВМЭ-350-3 & $\begin{array}{c}3 \text { мин } \\
\sim 600 \\
\text { проходов }\end{array}$ & $\sim 70$ & $21 \pm 13$ & 56 & $2-3$ & 3240 \\
\hline
\end{tabular}


Обработка микрокристаллической целлюлозы в течение 10 мин в планетарной мельнице «Активатор-4М» существенно уменьшает размер частиц - до 5 мкм (табл., рис. 1Б). Одновременно значительно разрушается часть кристаллической структуры образца при зарегистрированном уменьшении размеров ОКР до 2-3 нм и уменьшается индекс кристалличности ИК $\approx 39 \%$ (табл., рис. 2Б).

Для сравнения результатов при обработке микрокристаллической целлюлозы использовали также другую планетарную мельницу «Pulverizette 5». Поскольку данная мельница обладает меньшей мощностью, чем «Активатор-4М», время активации было увеличено в различных экспериментах с 15 до 40 мин. При времени воздействия 40 мин обработка целлюлозы в данной мельнице также приводит к существенному уменьшению ИК до 37 \% (табл., рис. ЗГ). Средний диаметр частиц целлюлозы в этом случае уменьшается с 114 до 13 мкм (табл., рис. 1Г). При этом для всех образцов наблюдается плавное уменьшение размеров частиц и индекса кристалличности с увеличением времени обработки (табл., рис. 1В, Г, рис. 2В, Г).

Таким образом, планетарные мельницы показали свою эффективность не только при измельчении частиц, но и при воздействии на микроструктуру целлюлозы. К существенным и неустранимым недостаткам планетарных мельниц относятся: длительность процесса активации и чрезвычайно высокие удельные затраты энергии.

Применение вихревой газодинамической мельницы для измельчения и активации биомассы привлекательно ввиду высокой скорости измельчения образца (процесс проходит в непрерывном режиме и для навески 100 г занимает около 2 с) при существенно меньших удельных затратах энергии по сравнению с планетарными мельницами. Простота конструкции вихревых мельниц является дополнительным важным фактором. После измельчения образца целлюлозы в вихревой мельнице ВМ-70 за 1 проход при давлении воздуха 4.5 атм и времени воздействия 2 с ИК изменился незначительно (до 86 \%) (табл., рис. 2Д,Е), а размер частиц составил 9 мкм (табл., рис. 1Д,Е), что сравнимо с размером частиц, полученных с помощью устройств «Активатор-4M» и «Pulverizette 5». При этом в вихревой мельнице ВМ-70 не происходит нагрева обрабатываемой целлюлозы, а, напротив, осуществляется её охлаждение до температуры примерно $10{ }^{\circ} \mathrm{C}$ за счет адиабатического расширения потока воздуха. Дополнительные проходы и увеличение давления воздуха до 5.5 атм не привели к заметным изменениям в размере частиц (табл.), однако наблюдается небольшое уменьшение значений ИК $\approx 85$ и ОКР $\approx 1-5$ (табл.).

Другая серия экспериментов по механической активации целлюлозы была проведена в вихревой мельнице «ВМЭ-350» при зарегистрированной температуре обработки около $70{ }^{\circ} \mathrm{C}$ (в планетарных мельницах образец может нагреваться до $100{ }^{\circ} \mathrm{C}$ и более). Ввиду достаточно большого объёма мельницы «ВМ-350», высокой липучести молотой целлюлозы, а также небольшого её суммарного количества эксперимент по обработке целлюлозы в «ВМЭ-350» проводился в следующем режиме: материал в количестве 100 г загружали внутрь мельницы, вход мельницы закрывали, после чего вращение крыльчатки поддерживали в течение 1 мин. При этом весь материал постепенно покидает помольную камеру мельницы и попадает в камеру сепарации. В данном режиме обеспечивается однократный проход материала через мельницу (время прохода $<<1$ c), при этом много материала налипает на внутренние поверхности мельницы. В данном случае практически не происходит разрушения кристаллической структуры 
целлюлозы (ИК $\approx 90$ \%) (табл., рис. 23 ), однако наблюдается уменьшение ОКР $\approx 2 \div 7$ и существенное уменьшение размера частиц до 40 мкм (табл., рис. 13).

Результаты обработки целлюлозы в последнем используемом типе мельниц, роторной мельнице «МАН-30», показали, что достигаемый размер частиц близок к полученному в предыдущих экспериментах с вихревой газодинамической мельницей (9 2 мкм) (табл., рис. 1Ж). При этом индекс кристалличности целлюлозы не претерпел изменений и составил исходные $90 \%$ (табл., рис. 2Ж).

Таким образом, наибольшее разрушение кристаллической структуры целлюлозы достигается активацией в планетарных мельницах, на что указывает существенное уменьшение размеров агрегатов частиц, размеров ОКР и понижение индекса кристалличности. При этом в вихревых мельницах происходит в основном разрушение агрегатов на составляющие при незначительном уменьшении индекса кристалличности. Также было обнаружено что при обработке в планетарных мельницах «Активатор-4М» и «Pulverizette 5» изменяется форма частиц. Частицы исходной кристаллической целлюлозы, а также частицы целлюлозы, обработанные в вихревых мельницах, имеют форму продолговатых кристаллов, в то время как целлюлоза, обработанная в планетарных мельницах, приобретает более сферическую форму. Данный эффект может быть объяснен различным характером ударного воздействия в мельницах разного типа (стесненный и свободный удар), а также различной интенсивностью (скорость удара) и длительностью обработки.

Хотя планетарные мельницы оказывают самое глубокое воздействие на микроструктуру обрабатываемой кристаллической целлюлозы, чрезвычайно длительное время активации и большое энергопотребление (до $2 \cdot 10^{5}$ Дж/кг) делают их применение экономически совершенно невыгодным для обработки реальной биомассы. Для измельчения и механической активации последней наиболее целесообразным представляется использование ударных вихревых мельниц с механическим разгоном материала, которые позволяют со значительно меньшими затратами энергии (около 1000 кДж/кг) и очень высокой скоростью проводить эффективное измельчение материала. Таким образом, для измельчения и активации древесных опилок была выбрана вихревая мельница «ВМЭ-350», обладающая самым низким удельным энергопотреблением и обеспечивающая высокую степень измельчения.

В качестве образцов реальной биомассы была использована высушенная древесина березы. Свежие поленья высушивали, измельчали с помощью циркулярной пилы (размер частиц составил $3 \pm 1.6$ мм) (табл., рис. 3А) и после дополнительно высушивали при комнатной температуре. Исследование полученных опилок методом РФА позволило определить индекс кристалличности ИК $\approx 74$ \% (табл., рис. ЗД). Достаточно низкое значение индекса кристалличности исходного образца объясняется наличием в древесине не только целлюлозы, но также лигнина и гемицеллюлозы.

Обработка опилок в вихревой мельнице «ВМЭ-350» проводилась в течение 1, 2 и 3 мин. При этом после загрузки материала вход мельницы соединялся с выходом с помощью гибкой трубы диаметром 0.1 м и длиной 3 м. Далее обработка материала проводилась в циклическом режиме. Учитывая объём мельницы, соединительной трубы и объёмную скорость воздуха, проходящего через мельницу, можно грубо оценить количество проходов материала через помольную зону мельницы в единицу времени - примерно 200 проходов/мин.

$$
-397-
$$


Уже за 1 мин удалось уменьшить размер агрегатов частиц примерно до 70 мкм (табл., рис. ЗБ), а ИК до 61 \% (табл.) при сохранении размеров ОКР в рамках погрешности измерений. Увеличение времени воздействия в два раза позволило уменьшить размер частиц до $22 \pm 13$ мкм (табл., рис. 3Г), а ИК до 56 \% (табл., рис. 3Е). Дальнейшее увеличение времени обработки не привело к последующим изменениям в размере частиц и степени их кристалличности.

\section{Заключение}

Проведено начальное исследование продуктов механического измельчения и активации образцов кристаллической целлюлозы и лигноцеллюлозной биомассы (высушенные берёзовые опилки) в мельницах различных конструкций. Полученные данные показывают, что при таком воздействии наблюдается частичный переход кристаллической целлюлозы в аморфное состояние при заметном уменьшении среднего размера частиц.

Проведенные исследования позволяют сравнить эффективность активации в мельницах различного типа. Наибольшее разрушение кристаллической структуры целлюлозы достигается активацией в планетарных мельницах, на что указывает существенное уменьшение размеров агрегатов частиц, размеров ОКР и понижение индекса кристалличности. Однако длительное время активации и чрезвычайно большое удельное энергопотребление делает их применение для измельчения и активации реальной биомассы экономически совершенно невыгодным. В то же время показано, что обработка кристаллической целлюлозы и высушенных берёзовых опилок в вихревых мельницах позволяет проводить очень быстрое и эффективное измельчение материала, однако с менее выраженным разрушением кристаллической структуры целлюлозы. При этом обработка материала в вихревых мельницах является гораздо (до 1000 раз) менее энергозатратной, что существенно повышает экономическую эффективность их потенциального использования.

Таким образом, дальнейшие исследования по механической активации ЛЦ-биомассы уместно проводить в ударных вихревых мельницах усовершенствованной конструкции с оптимизацией условий проведения измельчения и активации, например, за счёт увеличения скорости удара. Другим возможным направлением исследований может стать сочетание обработки в вихревой мельнице с последующей непродолжительной активацией материала в планетарной мельнице.

\section{Благодарности}

Работа выполнена при поддержке проекта базового бюджетного финансирования № V.46.4.4.

\section{Список литературы}

1. Klass D. L. Biomass for Renewable Energyю Fuels and Chemicals // Encyclopedia of Energy. Volume 1 / Cutler J. Cleveland. San Diego: Elsevier, 1998. P. 193-212.

2. Kamm B., Gruber P. R.,Kamm M. Biorefineries Industrial Processes and Products // Encyclopedia of Industrial Chemistry / Hubert Pelc. Weinheim: VCH Verlag, 2006. P. 659-683.

3. Deutschmann R.,Dekker R. F. H. From plant biomass to bio-based chemicals: Latest developments in xylan research // Biotechnology Advances. 2012. V. 30. N 6. P. 1627-1640.

$$
-398 \text { - }
$$


4. Heinze T. Chemical Functionalization of Cellulose // Polysaccharides. Structural diversity and functional versatility. Second edition / Severian Dumitriu. New York: Marcel Dekker, 2005. P. 551.

5. Ruppert A. M., Weinberg K.,Palkovits R. Hydrogenolysis Goes Bio: From Carbohydrates and Sugar Alcohols to Platform Chemicals // Angew. Chem. Int. Ed. 2012. V. 51. N 11. P. 25642601.

6. Gallezot P.,Kiennemann A. Conversion of Biomass on Solid Catalysts // Handbook of Heterogeneous Catalysis / Ertl. Wiley-VCH Verlag GmbH \& Co. KGaA, 2008. P. 2447-2476.

7. Bruggink A., Schoevaart R.,Kieboom T. Concepts of Nature in Organic Synthesis: Cascade Catalysis and Multistep Conversions in Concert // Organic Process Research \& Development. 2003. V. 7. N 5. P. $622-640$.

8. Fan L. T., Lee Y.-H.,Beardmore D. H. Mechanism of the enzymatic hydrolysis of cellulose: effects of major structural features of cellulose on enzymatic hydrolysis // Biotechnology and Bioengineering. 1980. V. 22. N 1. P. 177-199.

9. Jones E. O.,Lee J. M. Kinetic analysis of bioconversion of cellulose in attrition bioreactor // Biotechnology and Bioengineering. 1988. V. 31. N 1. P. 35-40.

10. Nailson M. J., Kelsey R. G.,Shafizaden F. Enhancement of enzymatic hydrolyses by simultaneous attrition of cellulosic substrates // Biotechnology and Bioengineering. 1982. V. 24. N 2. P. 293-304.

11. Ingesson H., Zacchi G., Yang B. et al. The effect of shaking regime on the rate and extend of enzymatic hydrolyses of cellulose // Journal of Biotechnology. 2001. V. 88. N 3. P. 177-182.

12. Elias C. B.,Joshi J. B. Role of hydrodynamic shear on activity and structure of proteins // Advances in Biochemical engineering. Biotechnology. 1998. V. 59. N P. 4-71.

13. Huang Z. Q., Xie X. L., Chen Y. et al. Ball-milling treatment effect on physicochemical properties and features for cassava and maize starches // Comptes Rendus Chimie. 2008. V. 11. N 1-2. P. 73-79.

14. Yeh A. I., Huang Y. C.,Chen S. H. Effect of particle size on the rate of enzymatic hydrolysis of cellulose // Carbohydrate Polymers. 2010. V. 79. N 1. P. 192-199.

15. http://www.activator.ru/Ac4M.html

16. http://www.fritsch-milling.com/products/milling/planetary-mills/pulverisette-54-classicline/description/

17. http://www.vortex-tech.ru/ProductList.html

18. http://www.vortex-tech.ru/Describe.html

19. Ким Д.А., Романов Н.А., Яворский А.И. Вихревой измельчитель для каскадного измельчения // Патент РФ 2386480, приоритет от 21.04.2008 г.

20. Аман С.О., Гольдштик М.А, Лебедев А.В, Правдина М.Х. Низкоскоростное ударное измельчение // Изв. СО АН СССР, сер. техн. Наук. 1989. Вып. 6. С. 51-57.

21. Правдина М.Х., Башкатов М.В. Расчетная модель двухфазного потока при измельчении твердой фазы в вихревой камере // Сибирский физико-технический журнал. 1993. Вып. 3. C. $48-55$.

22. M. Kh. Pravdina, A.I. Yavorsky, S.S. Pravdin, D.A. Kim, N.A. Romanov. The Statistical Model for Threshold Grinding in a Vortex Apparatus// XIV International Conference on the methods 
of aerophysical research (ICMAR XIV), June 30-July 6, 2008// Abstracts. Part II. 2008. pp.119-120. Novosibirsk.

23. Behrens D. //Chemie Ing/ Techn. 1965. Bd.37, N5.

24. The Cambridge Crystallographic Data Centre. Режим доступа: http://www.ccdc.cam.ac.uk/ pages/Home.aspx

25. Park S., Baker J. O., Himmel M. E. et al. Cellulose crystallinity index: measurement techniques and their impact on interpreting cellulase performance // Biotechnology for fuels. 2010. V. 3. N P. 10.

26. Scherrer P. Bestimmung der Grösse und der inneren Struktur von Kolloidteilchen mittels Röntgenstrahlen // Nachrichten von der Gesellschaft der Wissenschaften zu Göttingen. 1918. V. N 2. P. 98-100.

27. Wojdyr M. Fityk: a general-purpose peak fitting program // Journal of Applied Crystallography. 2010. V. 43. N 5-1. P. 1126-1128. 